\title{
Attitude towards Breastfeeding among Rural Women
}

\section{Kalaivnai P and Kali M Kalimo*}

Department of Social Science Extension Education, Avinashilingam Institute for Home Science and Higher Education for Women, Coimbatore, Tamil Nadu, India

\begin{abstract}
Attitudes and confidence among women can predict the duration of exclusive breastfeeding. The longer duration of breastfeeding, the more advantages there are for both mother and child. The aim of this study was to explore how the attitudes and the confidence were among breastfeeding mothers, impart scientific information and techniques of breastfeeding practices to the women and evaluate the impact of the programme. The total sample size of the study was 500 women were drawn from five blocks of Coimbatore district. From each block two Village Panchayats are chosen randomly to conduct the research. The data was collected from selected 500 women by face-to-face contact after agreeing to participate in the study. A main finding of the study is after the training programme on Attitude towards Breastfeeding, women had changed their negative attitude towards breastfeeding techniques. Women had much more positive attitudes towards breastfeeding.
\end{abstract}

Keywords: Breastfeeding Mother, Rural and Attitude

\section{Introduction}

Breastfeeding is the best way of providing ideal food for healthy growth and development of infants, and its advantages range from physiological to psychological for both mother and infants. It is wellknown that breastfeeding influences a child's health positively and improves nutritional status. A meta-analysis from three developing countries showed that infants who were not breastfed had a 6-fold greater risk of dying from infectious diseases within the first 2 months of life than those who were breastfed. Six months of exclusive breastfeeding and continued breastfeeding in first year of life could also prevent 1.3 million child deaths worldwide according to systematic reviews from the Bellagio Child Survival Study Group. In addition, incorrect infant feeding practices pose significant risk for malnutrition among children under the age of five.

The prevalence of breastfeeding differs from one country to another and from one society to another, this of course is due to cultural and religious believes. Delayed breastfeeding initiation, colostrum deprivation, supplementary feeding of breast milk substitutes, early introduction of complementary feeding, and incorrect weaning from breast milk are commonly found practices in communities around the world.

\section{Objectives of the Study}

- Explore how the attitudes and the confidence were among breastfeeding mothers

- Impart scientific information and techniques of breastfeeding practices to the women and

- Evaluate the impact of the programme.

\section{Methodology}

The cross-sectional study is conducted in the following areas of the Coimbatore district which is selected using Multi stage strata sampling techniques. The blocks are Karamadai, Annur, Thondamuthur, Madukarai, Sarkkarsamakkulam (Kovilpalayam) and Narachimmanaichenpalayam. From each block two Village Panchayats are chosen randomly to conduct the research.

Rapport was developed through frequent visits and discussions with Panchayat Presidents, Panchayat Level Federation Leaders, Self Help
Groups, Non-Governmental Organisations, School Head Masters, Integrated Child Development Scheme Officers, Child Development Programme Officers, Anganwadi Teachers, village people, to select the target people.

The total sample size of the study was 500 women were drawn from five blocks of Coimbatore district. Multi stage strata sampling techniques were used to select the area and sample for the study. Fifty women were chosen from each village Panchayat, Municipality and Corporation (10-Village Panchayats). The criteria used for the selection of the sample are mothers who have breastfeed their children at least for two years. Interview Schedule was used to collect data from the women. The prepared interview schedule was evaluated by the experts for standardization. The independent and dependent variables were identified, based on the data collected from the respondents.

The study was approved by the Institutional Human Ethics Committee, Avinashilingam Institute for Home Science and Higher Education for Women. The Approval Number is AUW/IHEC13-14/ XMT-04.

The data was collected from selected 500 women by face-to-face contact after agreeing to participate in the study. The collected data were consolidated, analysed and presented in Results and Discussion.

\section{Results and Discussion}

\section{Socio-economic characteristics of the women in rural areas}

Table 1 reveals the socio- economic characteristics of the respondents. It can be seen that a higher per cent of respondents belong to the age group of 18-23 years (47 per cent), followed by the 24-29 years (38 per cent) with the least per cent ( 1 per cent) seen in the age group of 35 and above. Majority of the households belonged to the

*Corresponding author: Kalimo KM, Department of Social Science Extension Education, Avinashilingam Institute for Home Science and Higher Education for Women, Coimbatore, Tamil Nadu, India, Tel: +91-8608369425; E-mail: pkvani12@gmail.com

Received June 06, 2018; Accepted June 20, 2018; Published June 26, 2018

Citation: Kalaivnai P, Kalimo KM (2018) Attitude towards Breastfeeding among Rural Women. Arts Social Sci J 9: 375. doi: 10.4172/2151-6200.1000375

Copyright: (c) 2018 Kalaivnai $\mathrm{P}$, et al. This is an open-access article distributed under the terms of the Creative Commons Attribution License, which permits unrestricted use, distribution, and reproduction in any medium, provided the original author and source are credited. 
Page 2 of 5

\begin{tabular}{|c|c|c|c|c|c|c|c|c|c|c|c|c|}
\hline \multirow[t]{4}{*}{ Characteristics } & & \multicolumn{10}{|c|}{ Blocks } & \multirow{4}{*}{$\begin{array}{c}\text { Avergae } \\
\text { percnetage } \mathrm{N}=500\end{array}$} \\
\hline & & \multicolumn{2}{|c|}{ Annur } & \multicolumn{2}{|c|}{ Koyilpalayam } & \multicolumn{2}{|c|}{ Karamadai } & \multicolumn{2}{|c|}{ Madukarai } & \multicolumn{2}{|c|}{ Thondamuthur } & \\
\hline & & \multicolumn{10}{|c|}{ Village Panchayats } & \\
\hline & & 1 & 2 & 3 & 4 & 5 & 6 & 7 & 8 & 9 & 10 & \\
\hline \multirow[t]{4}{*}{ Age (in years) } & $18-23$ & 40 & 46 & 64 & 58 & 40 & 44 & 52 & 42 & 42 & 44 & 47 \\
\hline & $24-29$ & 50 & 36 & 26 & 18 & 36 & 30 & 38 & 42 & 50 & 52 & 38 \\
\hline & $30-35$ & 10 & 18 & 10 & 18 & 24 & 26 & 10 & 16 & 8 & 4 & 14 \\
\hline & Above 35 & - & - & - & 6 & - & 6 & - & - & - & - & 1 \\
\hline \multirow[t]{3}{*}{ Religion } & Hindu & 94 & 86 & 90 & 100 & 90 & 86 & 92 & 92 & 94 & 90 & 91 \\
\hline & Muslim & 4 & 10 & - & - & 4 & 6 & - & 2 & 2 & - & 3 \\
\hline & Christian & 2 & 4 & 10 & & & 10 & 8 & 6 & 4 & 10 & 6 \\
\hline \multirow[t]{3}{*}{ Community } & Scheduled Caste (SC) & 52 & 48 & 52 & 28 & 52 & 28 & 54 & 50 & 52 & 40 & 46 \\
\hline & Most Backward caste (MBC) & 38 & 32 & 44 & 22 & 44 & 22 & 32 & 34 & 32 & 44 & 34 \\
\hline & Backward Caste(BC) & 10 & 20 & 4 & 50 & 4 & 50 & 14 & 16 & 16 & 16 & 20 \\
\hline \multirow[t]{2}{*}{ Family type } & Nuclear family & 36 & 30 & 46 & 82 & 40 & 30 & 36 & 36 & 30 & 38 & 40 \\
\hline & Joint family & 64 & 70 & 54 & 18 & 60 & 70 & 64 & 64 & 70 & 62 & 60 \\
\hline \multirow[t]{2}{*}{ Size of the family } & Small (4 members) & 32 & 36 & 46 & 82 & 46 & 82 & 42 & 34 & 32 & 30 & 46 \\
\hline & Large (More than 4 members) & 68 & 64 & 54 & 18 & 54 & 18 & 58 & 66 & 68 & 70 & 54 \\
\hline \multirow[t]{12}{*}{ Education (Head) } & Illiterate & 2 & 6 & 10 & 4 & 10 & 4 & 6 & 4 & 2 & & 4 \\
\hline & Primary school ( 1-5) & 20 & 18 & 46 & 6 & 44 & 52 & 20 & 10 & 20 & 20 & 26 \\
\hline & High school (6-10) & 22 & 26 & 20 & 58 & 20 & 14 & 20 & 10 & 23 & 18 & 23 \\
\hline & Higher secondary $(+12)$ & 22 & 20 & 8 & 10 & 16 & 10 & 20 & 22 & 22 & 14 & 16 \\
\hline & Diploma & 26 & 20 & 12 & 20 & 10 & 20 & 24 & 38 & 26 & 30 & 23 \\
\hline & College & 8 & 10 & 4 & 2 & - & - & 10 & 16 & 8 & 18 & 8 \\
\hline & Illiterate & 2 & 4 & 12 & & 12 & & 4 & & 2 & & 4 \\
\hline & Primary school (1-5) & 50 & 48 & 48 & 12 & 28 & 12 & 40 & 34 & 50 & 56 & 38 \\
\hline & High school (6 to 10$)$ & 36 & 30 & 36 & 20 & 36 & 46 & 38 & 40 & 36 & 30 & 35 \\
\hline & Higher secondary level $(+12)$ & 6 & 4 & - & 50 & 24 & 34 & 4 & - & 6 & - & 12 \\
\hline & Diploma & 6 & 14 & - & 8 & - & 8 & 14 & 26 & 6 & 14 & 10 \\
\hline & College & - & - & - & 10 & - & - & - & - & - & & 1 \\
\hline \multirow[t]{4}{*}{ Occupation (Head) } & Agriculture & 6 & - & 10 & 22 & 20 & 22 & 12 & 6 & 6 & & 10 \\
\hline & Coolie & 50 & 68 & 54 & 26 & 60 & 68 & 48 & 38 & 62 & 68 & 54 \\
\hline & Business & & - & & 8 & & & & 4 & 32 & 32 & 8 \\
\hline & Private sector & 44 & 32 & 36 & 44 & 20 & 10 & 40 & 52 & - & - & 28 \\
\hline Occupation (Women) & Housewives & 100 & 100 & 100 & 100 & 100 & 100 & 100 & 100 & 100 & 100 & 100 \\
\hline \multirow{3}{*}{$\begin{array}{l}\text { Income - Head } \\
\text { (per month in Rs) }\end{array}$} & $2500-5000$ & 58 & 74 & 30 & 12 & 30 & 20 & 62 & 50 & 72 & 74 & 48 \\
\hline & $5001-7500$ & 20 & 14 & 14 & 70 & 46 & 58 & 20 & 30 & 12 & 14 & 30 \\
\hline & Above 7500 & 22 & 12 & 56 & 18 & 24 & 22 & 18 & 20 & 16 & 12 & 22 \\
\hline \multicolumn{13}{|c|}{$\begin{array}{l}\text { 1: Machakowdampalayam; } 2 \text { : Kariyampalayam; } \\
\text { Theethipalayam; } 10 \text { : Maathampatti. } \\
\text { Source: Field survey } 2013\end{array}$} \\
\hline
\end{tabular}

Table 1: Socio-Economic Characteristics of the Women.

Hindu religion (91 per cent) while the Muslim community households were the lowest in the village Panchayats.

More than half of the respondents in all village Panchayats belonged to the scheduled caste; 44 per cent of the women were under the category of Most Backward Community (MBC); one fourth of the respondents ( 20 per cent) belonged to the Backward Classes (BC). About 60 per cent of the respondents lived in joint family system. More than 50 per cent of the respondents came from families which had four or more members.

With regard to the educational qualification of the respondents, it is seen that a high per cent of them had completed primary school (40 per cent) while 36 per cent of them had undergone high school education. One fourth of the respondents (20 per cent) were diploma holders and only 4 per cent were illiterates. Thirty per cent of the house-holds heads had completed the primary school level education, followed by 26 per cent who had finished their high school (X standard). Twenty per cent of the respondents had done their diploma education. Only nine per cent of the house-holds heads had completed their degree (Table 2).

Regarding the occupation of the respondents, it was seen that fifty per cent of head of the households were daily wage earners followed by the people in the private sector (30 per cent) while one forth of them (10 per cent) were working as agricultural labourers. All respondents were housewives (100 per cent). Fifty per cent of the head of the households were earning between Rs. 2500-5000/- while thirty per cent were earning in the range between Rs 5001-7000/-; only twenty per cent had an income above Rs 7500 .

To measure the attitudes among mothers towards infant feeding the Iowa Infant Feeding Attitude Scale (IIFAS) was developed [1]. The IIFAS contains 17 questions concerning attitudes about breastfeeding and formula feeding, where the women rate how much they agree or how much they disagree with the statement. The IIFAS was used to analyse the attitudes of expectant parents towards breastfeeding and 


\begin{tabular}{|c|c|c|c|c|}
\hline \multirow[t]{3}{*}{ Attitude } & \multirow{2}{*}{\multicolumn{3}{|c|}{$\begin{array}{c}\text { Rural (N:500) } \\
\text { paired differences }\end{array}$}} & \multirow[t]{3}{*}{$\mathrm{t}$ value } \\
\hline & & & & \\
\hline & Mean & SD & SEM & \\
\hline Prelactal practice delay the initiation of breastfeeding & 1.61 & 1.811 & 0.081 & $19.877^{\star *}$ \\
\hline Prelactal feeds hampers the proper establishment and future success of breastfeeding & 1.218 & 1.902 & 0.085 & $14.319^{\star *}$ \\
\hline Start breastfeeding within half an hour of birth & 1.218 & 1.861 & 0.08 & $14.652^{* *}$ \\
\hline Breastfeeding is a good contraceptive method if menstrual cycle is not started & 1.09 & 1.951 & 0.087 & $12.488^{* *}$ \\
\hline During breast feeding mother should be sit comfortably & 1.774 & 1.797 & 0.08 & $22.074^{\star \star}$ \\
\hline During breast feeding mother should maintain eye contact with the babay and also talk to her & 1.43 & 1.823 & 0.081 & $17.539^{* *}$ \\
\hline Wash each breast with warm water before breastfeeding & 1.584 & 1.779 & 0.079 & $19.908^{* *}$ \\
\hline Practice exclusive breastfeeding from birth to 6 months & 1.608 & 1.823 & 0.081 & $19.719^{\star \star}$ \\
\hline Milk flows from breasts when the mother thinks of her baby or hear her crying & 1.618 & 1.776 & 0.079 & $20.371^{* *}$ \\
\hline Machine should be used for expression of milk & 1.918 & 1.751 & 0.078 & $24.480^{\star \star}$ \\
\hline Expressed breast milk can be mixed with previous expressed milk & 1.44 & 1.856 & 0.083 & $17.347^{\star \star}$ \\
\hline Expressed can be warmed on fire & 1.496 & 1.797 & 0.08 & $18.606^{* *}$ \\
\hline Mother can produce enough milk to satisfy the baby's need & 1.584 & 1.755 & 0.078 & $20.178^{\star *}$ \\
\hline Mother should take medicine for breastfeeding problems according to doctor advice & 1.588 & 1.796 & 0.08 & $19.762^{\star \star}$ \\
\hline Breast milk is produced as a result of the interaction between hormones and reflexes & 1.802 & 1.775 & 0.079 & $22.692^{* *}$ \\
\hline Prolactin reflex increases mother's milk supply & 1.154 & 1.921 & 0.085 & $13.426^{\star *}$ \\
\hline More prolactin secreted at night time and it will help to suppress ovulation & 1.874 & 1.764 & 0.078 & $23.753^{\star *}$ \\
\hline Oxytocin reflex increases milk flow & 2.802 & 1.797 & 0.08 & $34.866^{\star \star}$ \\
\hline Oxytocin reflex helps in uterus contraction & 3.638 & 1.241 & 0.055 & $65.509^{* *}$ \\
\hline Breast feeding helps in mother and child bonding & 4.176 & 0.728 & 0.032 & $128.255^{\star *}$ \\
\hline Those using formula feeding will miss the greatest joy of motherhood & 3.822 & 0.883 & 0.039 & $96.775^{\star *}$ \\
\hline High calorie diet must be taken by all mothers at the time of lactation & 3.588 & 1.185 & 0.053 & $67.684^{* *}$ \\
\hline Breastfeeding should be given at an interval of 20 minutes & 2.648 & 1.809 & 0.08 & $32.721^{\star \star}$ \\
\hline Tension, pain and lack of confidence hinder the milk flow & 2.592 & 1.821 & 0.081 & $31.827^{\star *}$ \\
\hline
\end{tabular}

Table 2: Attitude towards Breastfeeding.

formula feeding. The IIFAS was shown to be a validated and reliable instrument. The result of the study also showed that the parents who were positive towards breastfeeding had a better attitude and a better knowledge about the advantages of breastfeeding [2].

The $t$ value of the following aspects were statistically significant at one per cent level Prelactal practice delay the initiation of breastfeeding, Prelactal feeds hampers the proper establishment and future success of breastfeeding, Start breastfeeding within half an hour of birth, Breastfeeding is a good contraceptive method if menstrual cycle is not started, during breastfeeding the mother should sit comfortably and maintain eye to eye contact with the baby and also talk with the child, Wash each breast with warm water before breastfeeding, Practice exclusive breastfeeding from birth to 6 months, Milk flows from breasts when the mother thinks of her baby or hears crying, Baby crying as a major sign of hunger, Machine should be used for expression of milk, Expressed breast milk can be mixed with previous expressed milk, functions of Prolactin and Oxytocin, benefits of breastfeeding, diet for lactating mother and psychological advice for successful breastfeeding.

Brown and Lee [3] explored the attitudes and experiences in mothers who successfully breastfed exclusively for six months. A positive attitude towards breastfeeding was associated with a longer duration of breastfeeding. High level of support, confidence and a natural determination to breastfeed had a connection to a positive attitude. The mothers were able to list several advantages with exclusive breastfeeding and that it was the natural and healthiest choice for both themselves and their infants. They also felt that they enjoyed it and that it created a closer bond between mother and infant.

After the training programme on Attitude towards Breastfeeding, women had changed their negative attitude towards breastfeeding techniques. Women had much more positive attitudes toward breastfeeding [4].

Wojcicki et al. [5] investigated maternal attitudes towards breastfeeding in San Francisco, California, by interviewing mothers who recently delivered a healthy new born. The main findings of the study showed that those participants who were using instant formula were more likely to have a negative attitude towards breastfeeding. Elements that promoted the negative attitude were embarrassment of breastfeeding in public, physical concerns, uncomfortable feelings and negative influence from family/friends. Stuebe \& Bonuck [6] also found comfort with breastfeeding in social environments and knowledge about the benefits of breastfeeding as factors related to the intension of exclusively breastfeeding. The authors suggested that strong reinforced messages about the health benefits of breastfeeding and strategies for encouraging breastfeeding in social environments should increase the duration and the exclusivity.

\section{Attitude towards breastfeeding in rural areas}

To find out the mean difference for the attitude towards breastfeeding before and after the training programme of the village Panchayats viz., Machakakowdampalayam, Kariyampalayam, Odanthurai, Chikaramapalyam, Malumichiampatti, Madukkarai, Vellamadai, Keeranatham, Theethipalayam and Mathampatti, the Paired sample t test was used [7].

The $t$ value of all the Panchayats was significant at one per cent level. It shows that there was a significant improvement in the attitude on breastfeeding after the training programme.

Maternal attitudes are better predictors of infant feeding method during the postpartum period. After the training programme women 
had a significantly higher total attitude score to breastfeeding preference than before the training programme (Table 3 ).

A research study on Knowledge, Attitude, and Practices of Breastfeeding and Weaning among Mothers of Children up to 2 Years Old in a Rural Area in El-Minia Governorate, Egypt conducted [8]. A community-based cross-sectional study was conducted on 307 rural mothers who have a youngest child aged 2 years or less. Mothers were selected using systematic random sampling. All the studied mothers knew that breastfeeding is the best nutritional source for the baby. The majority of the mothers had good knowledge about the advantages of breastfeeding for child. As regards weaning, majority (92.5\%) of the mothers defined weaning as breastfeeding cessation. Most of the mothers (94.8\%) agreed that breastfeeding protect child from infection, $96.1 \%$ agreed that it is the healthiest for infant, $76.5 \%$ agreed that breast milk lead to loss of figure, and $83.4 \%$ agreed that breastfeeding should be avoided during mother's illness. About $84 \%$ initiated breastfeeding immediately after delivery, and $42.7 \%$ of the studied mothers offered pre-lacteal feeds to baby before lactation. About thirty quarters $(74.2 \%)$ of mothers fed colostrum. Exclusive breast-feeding was found to be associated with mother's education $(\mathrm{P}<0.0001)$ but not with mothers age at birth, mother's occupation, or place of birth (Table 4 ).
A study on Breastfeeding attitudes and confidence among mothers in a rural area of Thailand conducted [9]. The outcome of the study demonstrated that the majority of the women had a neutral attitude towards breastfeeding, $13 \%$ had a positive attitude towards formula feeding and $7 \%$ had a positive attitude towards breastfeeding. No significance was found between mothers living with nuclear and extended family regarding the attitude. The majority rated high confidence in breastfeeding. Mothers who were living in nuclear families rated lower than mothers living in extended families in "refrain from bottle-feeding for the first 4 weeks" regarding confidence in breastfeeding.

The estimated equation was statistically significant at one per cent level. It could be identified from the significant $F$ value of various Panchayats. It indicated that all the selected variables together were statistically significant to explain the variations in attitude towards the breastfeeding.

The highest value of $\mathrm{R}^{2}$ was 0.82 for Kariyampalayam Panchayat. It means that attitude was explained by the selected Demographic factors along with breastfeeding to the extent of 82 per cent, this was followed by the Theethipalaym Panchayat with the value $R^{2}$ of 0.68 ,

\begin{tabular}{|c|c|c|c|c|}
\hline \multirow[t]{2}{*}{ Name of the Areas } & \multicolumn{3}{|c|}{ Paired Differences } & \multirow[t]{2}{*}{$\mathrm{t}$ value } \\
\hline & Mean & Std. Deviation & Std. Error Mean & \\
\hline Machakakowdampalayam & 30.36 & 17.915 & 2.533 & $11.983^{* *}$ \\
\hline Kariyampalayam & 39.3 & 49.819 & 7.045 & $5.578^{\star *}$ \\
\hline Odanthurai & 56.4 & 31.524 & 4.458 & $12.651^{* *}$ \\
\hline Chikarampalayam & 65.72 & 29.684 & 4.197 & $15.655^{\star *}$ \\
\hline Malumichampatti & 60 & 31.431 & 4.445 & $13.498^{* *}$ \\
\hline Madukarai & 6.022 & 32.458 & 4.59 & $13.119^{* *}$ \\
\hline Vellamadai & 6.142 & 31.547 & 4.461 & $13.767^{* *}$ \\
\hline Keeranatham & 64.82 & 31.34 & 4.432 & $14.625^{\star *}$ \\
\hline Theethipalayam & 61.12 & 31.614 & 4.47 & $13.671^{* *}$ \\
\hline Maathampatti & 5.926 & 33.571 & 4.747 & $12.482^{* *}$ \\
\hline
\end{tabular}

Table 3: Attitude towards breastfeeding in rural areas.

\begin{tabular}{|c|c|c|c|c|c|c|c|c|c|}
\hline \multirow[t]{2}{*}{ Name of the Areas } & \multicolumn{7}{|c|}{ Mean value } & \multirow[t]{2}{*}{ R Square } & \multirow[t]{2}{*}{ F value } \\
\hline & $\begin{array}{c}\text { Age } \\
\text { (in yrs) }\end{array}$ & Religion & Community & Family type & $\begin{array}{l}\text { Education } \\
\text { (Women) }\end{array}$ & $\begin{array}{l}\text { Occupation } \\
\text { (Head) }\end{array}$ & $\begin{array}{c}\text { Income-Head } \\
\text { (per month in Rs) }\end{array}$ & & \\
\hline \multirow[t]{2}{*}{ Machakakowdampalayam } & 1.318 & 0.106 & 2.182 & -3.714 & -1.482 & 1.329 & 1.329 & 0.67 & 4.891 \\
\hline & 0.195 & 0.916 & 0.035 & 0.001 & 0.146 & 0.191 & 0.191 & & 0 \\
\hline \multirow[t]{2}{*}{ Kariyampalayam } & 3.091 & 3.296 & -0.555 & 1.738 & -4.659 & -0.646 & 1.33 & 0.819 & 14.651 \\
\hline & 0.003 & 0.002 & 0.582 & 0.089 & 0 & 0.521 & 0.191 & & 0 \\
\hline \multirow[t]{2}{*}{ Odanthurai } & 0.408 & 1.356 & -4.006 & -0.513 & 1.605 & 1.218 & -0.999 & 0.47 & 4.544 \\
\hline & 0.685 & 0.183 & 0 & 0.611 & 0.116 & 0.23 & 0.324 & & 0.001 \\
\hline \multirow[t]{2}{*}{ Chikarampalayam } & 0.521 & 1.874 & -0.877 & -1.624 & -1.421 & 0.081 & 0.034 & 0.278 & 2.31 \\
\hline & 0.605 & 0.068 & 0.385 & 0.112 & 0.163 & 0.936 & 0.973 & & 0.044 \\
\hline \multirow[t]{2}{*}{ Malumichampatti } & 2.126 & 0.593 & 1.041 & -3.45 & -0.008 & -0.525 & 1.474 & 0.458 & 1.933 \\
\hline & 0.039 & 0.557 & 0.304 & 0.001 & 0.993 & 0.602 & 0.148 & & 0 \\
\hline \multirow[t]{2}{*}{ Madukarai } & 2.126 & 0.593 & 1.041 & -3.45 & -0.008 & -0.525 & 1.474 & 0.458 & 5.076 \\
\hline & 0.039 & 0.557 & 0.304 & 0.001 & 0.993 & 0.602 & 0.148 & & 0 \\
\hline \multirow[t]{2}{*}{ Vellamadai } & 2.651 & -0.49 & 0.848 & -2.376 & 0.461 & -0.509 & 1.045 & & 3.937 \\
\hline & 0.011 & 0.627 & 0.401 & 0.022 & 0.647 & & 0.302 & & 0.002 \\
\hline \multirow[t]{2}{*}{ Keeranatham } & 0.699 & -0.406 & 0.564 & -6.324 & 0.578 & -0.927 & 1.338 & 0.606 & 9.238 \\
\hline & 0.488 & 0.687 & 0.576 & 0 & 0.566 & 0.359 & 0.188 & & 0 \\
\hline \multirow[t]{2}{*}{ Theethipalayam } & 1.537 & -3.409 & -1.542 & -5.829 & -0.609 & 1.382 & -1.974 & & 12.912 \\
\hline & 0.132 & 0.001 & 0.131 & 0 & 0.546 & 0.174 & 0.055 & 0.683 & 0 \\
\hline \multirow[t]{2}{*}{ Maathampatti } & 1.225 & 0.725 & 1.542 & -4.02 & -1.096 & 1.041 & 0.627 & 0.414 & 4.235 \\
\hline & 0.227 & 0.472 & 0.131 & 0 & 0.279 & 0.304 & 0.534 & & 0.001 \\
\hline
\end{tabular}

Table 4: Impact of the selected demographic variables on attitude towards breastfeeding techniques among women in rural areas. 
which implies the attitude, was explained by the selected Demographic factors along with breastfeeding to the extent of 68 per cent.

The value of $\mathrm{R}^{2}$ was 0.67 for Machakowndampalayam Panchayat. It means that attitude was explained by the selected Demographic factors along with breastfeeding to the extent of 67 per cent.

A study was conducted in India for checking the knowledge, attitude and practices of infant feeding in south India on a group of 300 mothers whose baby's ages from 3 days to 17 months [10]. Only $32 \%$ of the mothers felt that milk should be the first feed, $6 \%$ considered prelactal fluids are necessary, $71 \%$ felt $4-5$ months is the optimal period of breast feeding exclusively and $78 \%$ said that cow's milk can be continued beyond one year as a regular food and proportion of mothers said breast feeding can be discontinued in case of maternal illness. The investigators concluded that still there is lack in the knowledge of mothers regarding exclusive breast feeding [11].

\section{Conclusion}

This study showed a lack of understanding of the importance of and poor adherence to exclusive breastfeeding for the first six months postpartum among rural mothers. As exclusive breastfeeding promotion has been proved to be one of most effective ways to improve infant survival, more attention should be given to it, especially targeting the large proportion of women who missed formal education on infant feeding in school. A proper community-based program including the tools for monitoring its implementation and effectiveness needs to be developed to transform policy recommendations into action in rural areas.

\section{References}

1. Mora LDA, Russel DW, Dungy Cl, Losch M, Dusdieker L (1999) The lowa
Infant Feeding Attitude Scale: Analysis of Reliability and Validity. J Community Appl Soc Psychol 29: 2362-2380.

2. Ebrahim B, Enezi AH (2011) Knowledge, Misconceptions, and Future Intentions towards Breastfeeding among Female University Students in Kuwait, J Hum Lact pp: 407-415.

3. Brown A, Lee M (2011) An Exploration of the Attitudes and Experiences of Mothers in the United Kingdom Who Chose to Breastfeed Exclusively for 6 Months Postpartum. Breastfeeding Med 6:197-204.

4. Idris NS, Sastroasmoro S, Hidayati F, Sapriani I, Suradi R, et al. (2012) Exclusive Breastfeeding Plan of Pregnant Southeast Asian Women: What Encourages Them? Breastfeeding Med, pp: 1-4.

5. Wojcicki JM, Gugig R, Tran C, Kathiravan S, Holbrook K, Heyman MB (2010) Early Exclusive Breastfeeding and Maternal Attitudes Towards Infant Feeding in a Population of New Mothers in San Francisco, California. Breastfeeding Med 5: 9-15.

6. Stuebe AM, Bonuck K (2011) What Predicts Intent to Breastfeed Exclusively? Breastfeeding Knowledge, Attitudes, and Beliefs in a Diverse Urban Population. Breastfeeding Med 6: 413-420.

7. Fadl Abul A, Shawky M, Taweel EIA, Cadwell K, Maffei TC (2012) Evaluation of Mothers' Knowledge, Attitudes, and Practice Towards the Ten Steps to Successful Breastfeeding in Egypt. Breastfeeding Med 7: 173-178.

8. Mohammed SE, Ghazawy RE, Hassan EE (2014) Knowledge, Attitude, and Practices of Breastfeeding and Weaning among Mothers of Children up to 2 Years Old in a Rural Area in El-Minia Governorate, Egypt conducted. J Family Med Prim Care 3: 136-140.

9. Johansson L, Hanna W (2013) Breastfeeding attitudes and confidence among mothers in a rural area of Thailand Thesis in Caring Science, Uppsala University, Department of public health and caring sciences. Section Caring Sci.

10. Kuzma (2013) Knowledge, attitude and practice related to infant feeding among women in rural Papua New Guinea: a descriptive, mixed method study. Int Breastfeeding J 8: 16.

11. Chandrashekar S, Chakaldar BK (1995) Infant feeding-Knowledge and attitudes in a rural areas of Karnataka. Indian J Paediatr 62: 707-712. 